\title{
Analisis Pemasaran Pinang Mentah di PT. Timor Mitra Niaga Desa Wederok Kecamatan Weliman Kabupaten Malaka
}

\author{
Maria Sarice Nahak ${ }^{\mathrm{a}}$, Agustinus Nubatonis ${ }^{\mathrm{b}}$ \\ ${ }^{a}$ Fakultas Pertanian, Universitas Timor, Kefamenanu, TTU - NTT, Indonesia, email: agustinusnubatonis74@gmail.com \\ ${ }^{b}$ Fakultas Pertanian, Universitas Timor, Kefamenanu, TTU - NTT, Indonesia, email: saricenahak06@gmail.com
}

\section{Article Info}

Article history:

Received 20 Mei 2019

Received in revised form 27 Mei 2019

Accepted 5 Juni 2019

DOI:

https://doi.org/10.32938/ag.v4i3.677

Keywords:

Pemasaran

Saluran Pemasaran

Fungsi Pemasaran

Margin Pemasaran

\section{Abstrak}

Pemasaran merupakan salah satu syarat pembangunan pertanian progresif. kelemahan dalam sistem pembangunan pertanian di negaranegara sedang berkembang termasuk Indonesia adalah kurangnya perhatian dalam bidang pemasaran. Tujuan dari penelitian ini adalah: 1) untuk mengetahui saluran pemasaran pinang mentah, 2) untuk mengetahui fungsi-fungsi pemasaran, 3) untuk mengetahui margin pemasaran pinang mentah di Timor Mitra Niaga Desa Wederok Kecamatan Weliman Kabupaten Malaka. Penelitian ini telah dilaksanakan pada bulan April-Mei 2018 di Timor Mitra Niaga Desa Wederok Kecamatan Weliman Kabupaten Malaka. Pengambilan sampe menggunakan metode Snowball Sampling. Data yang digunakan adalah data primer dan data sekunder. Metode analisis data adalah analisis desktiptif dan analisis margin pemasaran. Hasil penelitian diperoleh bahwa saluran pemasaran pinang mentah dari produsen lang sung ke konsumen dan produsen juga memasarkan pinang mentah melalui pedang pengecer. Fungsi-fungsi pemasaran yang dilakukan oleh pedagang pengecer adalah fungsi pembelian, fungsi penjualan, fungsi pengangkutan, fungsi penyimpanan, fungsi standarisasi dan grading, fungsi permodalan, fungsi penanggungan resiko dan fungsi informasi pasar, sedangkan produsen pinang mentah melakukan fungsi penjualan, fungsi standarisasi dan grading, dan fungsi penanggungan resiko. Margin pemasaran pinang mentah sebesar Rp 5.000/kg atau $50 \%$ dari harga yang dibayar oleh konsumen.

\section{Pendahuluan}

Pemasaran adalah konsep sosial dan manajerial yang membuat individu dan kelompok memperoleh apa yang mereka butuhkan serta inginkan lewa penciptaan dan pertukaran timbal balik produk dan nilai dengan orang lain. Sedangkan pasar adalah salah satu dari bagian sistem, intuisi, prosedur dan hubungan sosial dimana usaha menjual barang, jasa dan tenaga untuk orangorang dengan imbalan uang (Susanto dan Kotler, 2000). Selain Susanto dan Kotler terdapat banyak ahli yang memberikan konsepnya tentang pemasaran, namun Anindita (2004) menegaskan bahwa paling tidak ada tiga hal yang perlu menjadi perhatian dalam konsep pemasaran, yaitu adanya kegiatan, produsen dan konsumen.

Pemasaran yang baik adalah pemasaran yang terlebih dahulu mengenal konsumen atau dengan kata lain pemasaran harus diawali dengan identifikas kebutuhan konsumen, sehingga pemasaran harus berorientasi kepada pelanggan, bukan pada produk (Hanafie, 2010). Pada intinya pemasaran bertujuan menghantarkan produk dari titik produsen ke konsumen. Salah satu komoditi pertanian yang telah dipasarkan secara luas yaitu buah pinang.

Pinang merupakan salah satu komoditi perkebunan yang di ekspor ke berbagai negara yang membutuhkan. Kebutuhan dunia akan pinang sekitar $80 \%$ dipenuhi dari Indonesia, melalui kegiatan ekspor. Menurut Sari (2018) bahwa kegiatan ekspor tersebut berkaitan dengan tingkat keuntungan pengusahaan komoditi terseburt relatif lebih baik dan juga kebijakan pemerintah untuk mendorong perluasan areal komoditi tersebut guna meningkatkan jumlah produksi. Selain diekspor, buah pinang di Indonesia juga dikonsumsi oleh masyarakat lokal. Pemanfaatan buah pinang sudah dikenal sejak dahulu oleh nenek moyang kita, yaitu untuk mengatasi mulut kering, menguatkan gigi dan gusi, obat cacing, mengobati kulit yang luka, rabun mata, mengobati sakit pinggang. Banyaknya manfaat dari buah pinang maka tiap tahunnya permintaan dan kebutuhan buah pinang semakin meningkat (Kanista, 2013).

Masyarakat lokal di Timor selain menggunakan atau mengkonsumsi buah pinang untuk kepentingan kesehatan, pinang juga memiliki nilai penting lainnya, baik sebagai kebiasaan atau tradisi penghormatan, persahabatan dan jamuan untuk tamu, yang disebut dengan lo'e. Buah pinang juga digunakan untuk berbagai keperluan adat, acara pernikahan, maupun acara-acara lainya yang berhubungan dengan kebudayaan dan adat istiadat masyarakat sebagai bahan konsumsi yang disebut dengan makan sisih (mam) yang dicampur dengan sirih dan kapur (Naimena dan Nubatonis, 2017).

Salah satu kabupaten di Timor adalah kabupaten Malaka yang berbatasan langsung dengan kabupaten Belu, TTU dan TTS serta Negara Timor Leste memiliki tradisi konsumsi pinang yang tidak berbeda dengan kebanyakan masyarakat Timor, yaitu sebagai bahan hidangan untuk berbagai jamuan yang disebut dengan look

Desa Wederok adalah bagian dari kabupaten Malaka dengan mayoritas masyarakatnya juga mengkonsumsi buah pinang. Sumber daya alam berupa tanah dan air yang cukup tersedia maka hadirlah suatu usaha produksi buah pinang mentah dengan nama Timor Mitra Niaga yang telah menghasilkan buah pinang mentah untuk memenuhi kebutuhan konsumsi masyarakat sekitarnya. Produksi pinang Timor Mitra Niaga pada tahun 2015 sebanyak $28.855 \mathrm{~kg}$, pada tahun 2016 diproduksi sebanyak $44.720 \mathrm{~kg}$, pada tahun 2017 diproduksi sebanyak $53.735 \mathrm{~kg}$ sedangkan harga jual adalah sebesar Rp 4.000/kg pada tahun 2016 dan Rp 5.000 pada tahun 2017 (Timor Mitra Niaga, 2018). Data tersebut menunjukan bahwa produksi dan harga pinang mentah mengalami peningkatan dari tahun ke tahun.

Produksi buah pinang dipasarkan dalam bentuk segar atau disebut dengan pinang mentah melalui saluran langsung ke konsumen disekitar kebun Timor
Mitra Niaga maupun lewat pedagang perantara. Kehadiran pedagang perantara dalam pemasaran pinang menimbulkan sejumlah aktivitas berupa fungsi-fungsi pemasaran dan pedagang akan memperoleh balas jasa berupa keuntungan yang merupakan bagian tak terpisahkan dari margin pemasaran. Saluran pemasaran yang panjang melibatkan banyak lembaga pemasaran, sehingga semakin panjang saluran pemasaran, harga di tingkat konsumen akan semakain tinggi, sehingga keuntungan dari tingginya harga tidak dinikmati petani melainkan pedagang perantara (Sari). Menurut Hanafie (2010) mengatakan bahwa tinggi-rendahnya margin pemasaran dipakai untuk mengukur efisiensi sistem pemasaran. Makin tinggi margin pemasaran maka makin tidak efisien sistem pemasaran tersebut.

Sejauh ini di Kabupaten Malaka dan sekitarnya telah dilakukan penelitian pada aspek budidaya yang dilakukan oleh Liat (2016) dan Nainahas dan Taolin (2017), sedangkan penelitian tentang pemasaran pinang telah dilakukan oleh Naimena dan Nubatonis (2017) yaitu pemasaran pinang kering di kecamatan Kota Kefamenanu Kabupaten TTU yang merupakan kabupaten tetangga langsung dengan Kabupaten Malaka.

Beberapa hal yang dapat diuraikan dari penelitian Naimena dan Nubatonis (2017) menunjukan bahwa saluran pemasaran pinang kering oleh pedagang $\mathrm{d}$ Kecamatan Kota Kefamenanu, Kabupaten TTU yakni Pedagang Besar mendatangkan pinang kering dari luar daerah dan memasarkan ke konsumen akhir. Selain itu Pedagang Besar juga memasarkan pinang kering melalui Pedagang Pengecer dan selanjutnya Pedagang Pengecer memasarkan ke Konsumen akhir. Fungsi yang dilakukan oleh Pedagang Besar adalah fungsi penjualan dan fungsi penyimpanan, pengangkutan, penyediaan dana penanggung risiko, dan informasi pasar, sedangkan fungsi yang dilakukan oleh pedagang Pengecer yaitu fungsi pembelian, penjualan, penyimpanan, pengangkutan, standarisasi dan grading, penanggung risiko, informasi pasar, dan penyediaan dana. Margin pada tingkat Pedagang Besar sebesar Rp. 9.000/kg dengan harga jual beli sebesar Rp. $31.000 / \mathrm{kg}$ dan harga jual sebesar Rp. 40.000/kg, sedangkan margin pada tingkat Pengecer sebesar Rp. 20,000/kg dengan harga beli sebesar Rp. 40.000/kg dan harga jual sebesar Rp. 60.000/kg.

Berdasarkan uraian dari latar belakang di atas maka peneliti tertarik untuk melakukan penelitian dengan judul: Analisis Pemasaran Pinang Mentah Di PT. Timor Mitra Niaga Desa Wederok Kecamatan Weliman Kabupaten Malaka. Adapun tujuan dari penelitian ini adalah: 1) untuk mengetahui saluran pemasaran pinang mentah, 2) untuk mengetahui fungsi-fungsi pemasaran, 3) untuk mengetahui margin pemasaran pinang mentah di Timor Mitra Niaga Desa Wederok Kecamatan Weliman Kabupaten Malaka.

\section{Metode}

Penelitian ini telah dilaksanakan pada bulan April-Mei 2018 di Timor Mitra Niaga Desa Wederok Kecamatan Weliman Kabupaten Malaka. Pengambilan sampel menggunakan metode Snowball Sampling pada pedagang pinang mentah, jumlah sampel yang diambil sebanyak 5 responden. Data yang digunakan adalah data primer dan data sekunder. Data primer bersumber dar Timor Mitra Niaga dan pedagang perantara yang diperoleh dengan teknik wawancara dengan berpedoman pada daftar pertanyaan atau kuisioner. Data sekunder diperoleh dari instansi-instansi terkait.

Metode analisis data adalah analisis desktiptif untuk mencapai tujuan 1 dan tujuan 2 yang berpedoman pada petunjuk Anindita (2004), Sudiyono (2002) sedangkan untuk tujuan 3 menggunakan analisis margin pemasaran sesuai petunjuk Anindita (2004). 


\section{Hasil dan Pembahasan}

\subsection{Saluran pemasaran}

Saluran pemasaran memberikan gambaran tentang saluran sebagai suatu rute atau jalur (Swasta dan Irawan, 2001), yaitu sebagai sekelompok pedagang dan agen perusahaan yang mengkombinasikan antara pemindahan fisik dan nama dari suatu produk untuk menciptakan kegunaan bagi pasar tertentu.

Pemasaran pinang oleh Timor Mitra Niaga melalui 2 saluran, yaitu pemasaran langsung ke konsumen maupun melalui pedagang perantara satu tingkat pasar dengan melibatkan pedagang pengecer. Saluran pemasaran pinang mentah dari produsen sampai kepada konsumen akhir, ditunjukan pada gambar 1.

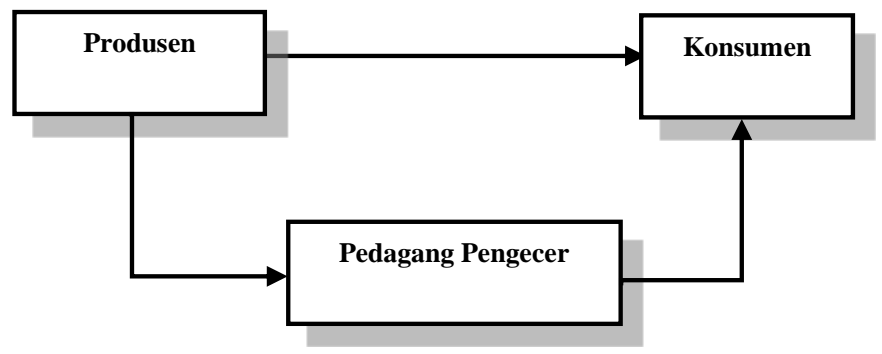

Gambar 1. Saluran Pemasaran Pinang Mentah di Timor Mitra Niaga berikut:

Saluran pemasaran pinang mentah pada gambar 1 dapat dijelaskan sebagai

\section{Saluran I (Produsen - Konsumen)}

Pemasaran pinang mentah oleh produsen pada saluran ini, yaitu pinang mentah dari tangan produsen dipasarkan langsung ke tangan konsumen akhir dalam satuan eceran, dengan harga Rp.5.000/kg. Pinang mentah yang sudah berada di tangan konsumen digunakan untuk keperluan konsumsi sendiri dan untuk menjamu tamu.

Terdapat pula satu model pemasaran pinang ke konsumen, berupa satuan pinang dalam bentuk tangkai atau rangkai. Pemasaran dengan model tersebut untuk melayani konsumen dengan kebutuhan tertentu, yaitu untuk keperluan acara adat terutama acara peminangan mempelai perempuan dan pernikahan. Harga per rangkai adalah sebesar Rp.25.000 dengan berat pinang per rangkai 5 $\mathrm{kg}$.

\section{Saluran II (Produsen - Pedagang Pengecer - Konsumen)}

Pada saluran pemasaran jenis ini, produsen memasarkan pinang mentah melalui pedagang pengecer dan pedagang pengecer memasarkannya ke konsumen akhir. Produsen memasarkan pinang mentah secara partai, yaitu dalam satuan karung dengan berat $40 \mathrm{~kg} / \mathrm{karung}$ ke pedagang. Harga per karung Rp.200.000 dan cara pembayaran tunai.

Pinang mentah yang sudah beralih tangan dari produsen ke pedagang, selanjutnya pedagang memasarkan secara eceran ke konsumen pada tiga pasar mingguan, yaitu pasar Besikama pada hari Senin, pasar Bestaek pada hari Rabu dan pasar Betun pada hari Sabtu. Pemasaran pinang oleh pedagang menggunakan satuan tumpuk dengan harga Rp.5.000/tumpuk (berat pinang per tumpuk $0,5 \mathrm{~kg}$ ) dan satuan kilogram dengan harga Rp.10.000 dan cara pembayaran tunai.

\subsection{Fungsi-Fungsi Pemasaran}

Fungsi-fungsi pemasaran merujuk pada serangkaian kegiatan dan tindakan yang ditujukan untuk menggerakan barang dalam hal ini komoditi pertanian dari titik produsen ke titik konsumen agar terjadi peningkatan nilai guna bentuk, guna waktu maupun guna tempat. Pada prinsipnya fungsi-fungsi pemasaran dikategorikan atas tiga, yaitu fungsi pertukaran, fungsi fisik dan fungsi penyediaan fasilitas (Anindita, 2004). Hasil penelitian tentang fungsifungsi pemasaran yang dilakukan oleh produsen maupun pedagang ditunjukan pada tabel 1 .

Tabel 1 menunjakan bahwa fungsi-fungsi pemasaran yang dilakukan oleh produsen adalah fungsi penjualan, fungsi standarisasi dan grading, dan fungsi penanggungan resiko, sedangkan pada tingkat pedagang menjalankan fungsi-fungsi pemasaran pinang mentah berupa fungsi pembelian, fungsi penjualan, fungsi pengangkutan, fungsi penyimpanan, fungsi standarisasi dan grading, fungsi permodalan, fungsi penanggungan resiko dan fungsi informasi pasar. Baik produsen maupun pedagang melakukan fungsi penjualan, fungsi standarisasi dan grading, dan fungsi penanggungan resiko. Selanjutnya hasil penelitian akan diuraikan sebagai berikut.

\section{Fungsi Pertukaran}

Fungsi pertukaran dalam pemasaran produk-produk pertanian meliput kegiatan yang menyangkut pengalihan hak pemilikan dalam sistem pemasaran (Sudiyono, 2002). Fungsi pertukaran terdiri atas 2 fungsi, yaitu fungsi pembelian dan fungsi penjualan.

a. Fungsi Pembelian

Fungsi pembelian tidak dilakukan oleh produsen, tetapi dilakukan oleh pedagang pengecer. Produsen pinang tidak melakukan fungsi pembelian karena merekalah yang menghasilkan pinang dan menjual ke konsumen maupun pedagang pengecer. Pedagang pengecer membeli pinang mentah dari produsen dalam satuan Rp.200.000/karung. Berat bersih 1 karung pinang adalah seberat $40 \mathrm{Kg}$. Dengan demikian harga beli pinang pada tingkat produsen per kilogram adalah sebesar Rp.5.000. Cara pembayaran oleh pedagang ke produsen secara tunai di lokasi produsen. Dalam seminggu pedagang membeli pinang sebanyak 3 kali atau 12 kali dalam sebulan.

\section{b. Fungsi Penjualan}

Penjualan pinang mentah oleh produsen dalam dua macam, yaitu secara eceran dan partai. Penjualan pinang mentah secara eceran biasanya dari tangan produsen langsung ke konsumen untuk keperluan konsumsi sendiri dan untuk menjamu tamu dengan harga jual Rp.5.000/kg. Penjualan pinang mentah secara partai biasanya dari tangan produsen ke pedagang dengan satuan penjualan adalah Rp.200.000/karung. Dalam 1 karung terisi pinang seberat 40 Kg. Dengan demikian tidak ada perbedaan harga jual pinang pada tingkat produsen, baik yang dijual langsung ke konsumen maupun melalui padagang pengecer, yaitu Rp.5.000/kg.

Terdapat pula satu model penjualan pinang ke konsumen, berupa penjualan pinang dalam bentuk atau satuan penjualan tangkai atau rangkai. Penjualan pinang dengan model tersebut untuk melayani konsumen dengan kebutuhan tertentu, yaitu untuk keperluan acara adat terutama acara peminangan mempelai perempuan. Harga jual per rangkai adalah sebesar Rp.25.000 dengan berat pinang per rangkai $5 \mathrm{~kg}$.

Fungsi penjualan pinang yang dilakukan oleh pedagang berupa pedagang menjual pinang secara eceran ke konsumen pada tiga pasar mingguan, yaitu pasar Besikama pada hari Senin, pasar Bestaek pada hari Rabu dan pasar Betun pada hari Sabtu. Penjualan pinang oleh pedagang menggunakan satuan tumpuk dengan harga Rp.5.000/tumpuk dan satuan kilogram dengan harga Rp.10.000. Berat pinang per tumpuk $0,5 \mathrm{~kg}$ atau 2 tumpuk pinang setara dengan $1 \mathrm{~kg}$ pinang, sehingga harga jual per kg adalah sebesar Rp.10.000.

Tabel 1. Fungsi-Fungsi Pemasaran Yang Dilakukan Oleh Produsen danPedagang Dalam memasarkan Pinang Mentah oleh Timor Mitra Niaga

\begin{tabular}{llcc}
\hline No & Fungsi Pemasaran & Produsen & Pedagang \\
\hline 1 & Fungsi Pertukaran & & \\
& a. Penjualan & $\checkmark$ & $\checkmark$ \\
& b. Pembelian & & $\checkmark$ \\
\hline 2 & Fungsi Fisik & & \\
\hline & a. Pengangkutan & $\checkmark$ \\
b. Penyimpanan & & \\
\hline 3 & Fungsi Penyediaan Fasilitas & & $\checkmark$ \\
\hline & a. Standarisasi dan grading & $\checkmark$ & $\checkmark$ \\
& b. Permodalan & & $\checkmark$ \\
& c. Penanggungan resiko & $\checkmark$ & $\checkmark$ \\
\hline & d. Informasi pasar & & \\
\hline
\end{tabular}

Sumber : Olah Data Primer (2019)

2. Fungsi Pengadaan Secara Fisik

Fungsi pengadaan secara fisik disebut juga dengan fungsi fisik. Fungsi fisik meliputi kegiatan-kegiatan yang secara langsung diperlakukan terhadap komoditi pertanian didalam pemasaran, sehingga komoditi pertanian mengalami tambahan guna tempat dan guna waktu. Mengacu pada uraian tersebut maka Sudiyono (2002) membagi fungsi fisik atas fungsi penyimpanan dan fungsi pengangkutan. Lain halnya dengan Anindita (2004) yang mengatakan bahwa, fungsi fisik selain meliputi tambahan guna tempat dan waktu juga terdapat guna bentuk berupa perubahan fisik dari produk pertanian, sehingga melahirkan fungsi fisik ketiga yaitu fungsi pengolahan komoditi pertanian.

Hasil penelitian menunjukan bahwa terdapat 2 fungsi fisik, yaitu fungsi pengangkutan dan fungsi penyimpanan, sedangkan fungsi pengolahan tidak dilakukan, dalam arti tidak terdapat perlakukan khusus terhadap bentuk pinang mentah.

a. Fungsi Pengangkutan

Fungsi pengangkutan terutama berkenaan dengan penyediaan barang pada tempat yang sesuai, termasuk didalamnya kegiatan bongkar dan muat barang (Anindita, 2004), sehingga fungsi ini meliputi perencanaan, pemilihan dan pergerakan alat-alat transportasi dalam pemasaran produk-produk pertanian Sudiyono (2002).

Fungsi pengangkutan pinang mentah dilakukan oleh pedagang pengecer, sedangkan produsen tidak melakukan fungsi pengangkutan. Fungsi ini termasuk kegiatan bongkar dan muat barang, proses pengangkutan pinang mentah dimuat dari tempat atau lokasi produsen pinang ke rumah pedagang hingga dipasarkan ke konsumen akhir di tiga lokasi pasar, yaitu pasar Besikama pada hari Senin, pasar Bestaek pada hari Rabu dan pasar Betun pada hari Sabtu.

b. Fungsi Penyimpanan

Penyimpanan pinang oleh pedagang sangat sederhana, yaitu pinang yang dibeli dari produsen dikemas dalam karung dengan kapasitas $40 \mathrm{~kg} /$. Penyimpanan pinang mentah tidak terdapat perlakuan khusus dalam penyimpanan dalam menjaga kualitas pinang karena pinang dapat bertahan beberapa hari jika disimpan di tempat yang terhindar dari suhu tinggi atau terik sinar matahari langsung dan tempat yang lembab atau basah serta pinang dianginkan sehingga terhindar dari pembusukan. Penyimpanan dilakukan karena pinang belum habis terjual ke konsumen.

Fungsi penyimpanan pinang tidak berkaitan dengan pernyataan untuk memenuhi kebutuhan konsumsi dari waktu ke waktu (Sudiyono, 2002) atau barang tersebut tersedia pada waktu yang diinginkan (Anindita, 2004). Dalam konteks tersebut tidak dilakukan karena produksi pinang mentah atau pinang segar tidak berlebihan, setiap musim panen tiba akan selalu habis terjual. Hal ini 
dapat terjadi karena pinang bagi masyarakat Timor kebutuhannya sangat besar, baik untuk kebutuhan konsumsi rumah tangga, menjamu tamu dan berbagai kegiatan adat, seperti sesajian untuk arwah, tuan tanah (penjaga alam semesta), pinangan dan lain-lainnya.

3. Fungsi Penyediaan Fasilitas

Fungsi penyediaan fasilitas merupakan usaha-usaha perbaikan sistem pamasaran untuk meningkatkan efisiensi operasional dan efisiensi penetapan harga. Hasil penelitian diperoleh bahwa fungsi pemasaran dalam kelompok fungsi penyediaan fasilitas ini meliputi: fungsi standardisasi dan grading, penyediaan dana, penanggung resiko dan fungsi informasi pasar.

a. Fungsi Standardisasi dan Grading

Standardisasi merupakan penetapan tingkatan berdasrkan kriteria atau spesifikasi kualitas tertentu dari komoditi pertanian, sedangkan grading merupakan proses pemisahan produk pertanian berdasrkan salah satu atau beberapa kriteria kualitas atau sifat produk pertanian. (Sudiyono, 2002, Anindita, 2004)

Fungsi standardisasi dan grading membantu pembelian dan penjualan barang yang memungkinkan dilakukan transaksi hanya melalui contoh dan diskripsi dari suatu produk (Anindita, 2004), sehingga dapat meningkatkan efisiensi pemasaran sebab dapat memberikan deskripsi barang secara jelas, menghilangkan waktu dan biaya. (Sudiyono, 2002).

Fungsi standardisasi dan grading sangat sederhana, baik pada tingka produsen maupun pedagang. Buah pinang yang dipanen oleh produsen dibersihkan dan dipisahkan dari rangkai dan tangkainya. Standardisasi yang dilakukan oleh produsen berupa satuan penjualan dalam kilogram, tidak membedakan berdasarkan ukuran besar-kecil dan warna kulit buah pinang. Harga jual perkilogram pada tingkat produsen sebesar Rp.5.000.

Terdapat pula satu standar penjualan pinang ke konsumen, berupa penjualan pinang dalam bentuk atau satuan penjualan tangkai atau rangkai. Penjualan pinang dengan model tersebut untuk melayani konsumen dengan kebutuhan tertentu, yaitu untuk keperluan acara adat terutama acara peminangan mempelai perempuan. Harga jual per rangkai adalah sebesar Rp.25.000 dengan berat pinang per rangkai $5 \mathrm{~kg}$.

Pedagang dalam melakukan fungsi standardisasi dan grading berdasarkan satuan penjualan kilogram dan tumpukan. Satuan penjualan dalam kologram, tidak membedakan berdasarkan ukuran besar-kecil dan warna kulit buah pinang, sedangkan satuan penjualan dalam bentuk tumpukan dibedakan atas dua, yaitu tumpukan buah pinang ukuran besar sebanyak 12 buah dan tumpukan buah pinang ukuran kecil sebanyak 20 buah. Baik tumpukan dengan buah pinang ukuran besar maupun tumpukan dengan buah pinang ukuran kecil jika ditimbang beratnya sama yaitu 0,5 kilogram. Harga jual pada tingkat pedagang sebesar Rp $10.000 / \mathrm{kg}$ dan harga jual per tumpuk Rp 5.000 .

b. Penyediaan dana

Dalam memasarkan suatu produk, seringkali terkendala akibat kurang modal untuk melakukan transaksi-transaksi. Modal atau dana yang digunakan produsen bersumber dari modal milik sendiri, sedangkan modal pedagang dalam memasarkan pinang mentah bersumber dari modal milik sendiri maupun dari pinjaman.

Modal pinjaman oleh pedagang dengan perjanjian pengembalian dengan periode pengembalian dalam periode mingguan, sehingga mereka sering menakan model pinjaman tersebut sebagai pinjaman mingguan. Besarnya pinjaman sebanyak Rp.2.500.000, cara pembayan pinjaman perminggu dengan besarnya Rp.65.000, sehingga untuk melunasi uang pinjamannya pedagang melakukan pembayarannya selama 11 bulan atau 44 minggu dengan total pengembalian pinjaman sebanyak Rp 2.860.000. Dengan demikian dapat dihitung besarnya bunga pinjaman, yaitu sebesar Rp.360.000 atau sebesar 14,4\% c. Penanggung Resiko

Penanggung resiko tidak dialami oleh produsen karena pinang yang dipanen langsung terjual ke pedagang, sehingga tidak terjadi penyimpanan pinang dalam jangka waktu yang lama. Penanggung resiko tidak dialami oleh pedagang karena pinang yang dibeli dari produsen akan habis terjual ke konsumen dalam waktu 2-3 hari, sehingga tidak terjadi penyimpanan pinang dalam jangka waktu yang lama. Untuk terhindar dari kerusakan, pedagang menyimpan pinang pada tempat yang terbuka dan terhindar dari suhu panas atau matahari.

d. Informasi Pasar

Informasi pasar sering disalah artikan sebagai informasi harga, padahal informasi pasar menurut Sudiyono (2002) selain menyangkut harga komoditi per satuan, sebaiknya juga menginformasikan mengenai persedian, kualitas komoditi di tingkat pasar pada tempat dan waktu tertentu.

Hasil penelitian menunjukan bahwa pada fungsi informasi pasar, hal yang paling diperhatikan adalah informasi harga dan penyediaan pinang mentah $\mathrm{d}$ tingkat produsen dan persediaan pinang di tingkat pedagang. Informasi dijaring diantara para pedagang dengan produsen. Pedagang menginformasikan mengenai persediaan atau stok pinang mentah di tangan mereka, jika pinang hampir habis terjual akan diinformasikan ke produsen agar dilakukan pemetikan untuk melayani pesanan dari para pedagang. Ini dilakukan dengan tujuan untuk menjaga kedua belah pihak agar tidak mengalami kerugian.

\subsection{Margin Pemasaran}

Margin pemasaran pinang mentah merupakan selisih antara harga yang di bayar oleh konsumen dan harga yang diterima produsen, sehingga margin pemasaran terdiri atas dua komponen yaitu komponen biaya pemasaran dan komponen keuntungan lembaga pemasaran.

Dilihat dari saluran pemasaran pinang mentah di PT. Timor Mitra Niaga yang bervariasi, maka margin pemasaran juga sangat bervariasi seiring dengan berbedanya pemasaran pinang mentah. Margin pemasaran yang terjadi pada setiap saluran pemasaran sebagai berikut

Tabel 2. Distribusi Margin Pemasaran Pinang Mentah Di Timor Mitra Niaga

\begin{tabular}{|c|c|c|c|c|}
\hline \multirow[t]{2}{*}{ Uraian } & \multirow{2}{*}{$\begin{array}{l}\text { Nilai } \\
\text { Rp/kg }\end{array}$} & \multicolumn{3}{|c|}{ Distribusi Margin } \\
\hline & & Nilai $(\mathrm{Rp} / \mathrm{kg})$ & & $(\%)$ \\
\hline Harga jual & 10.000 & & & \\
\hline Harga Beli ....................... & 5.000 & & & \\
\hline $\begin{array}{l}\text { Margin Pemasaran } . . . \ldots \ldots \ldots \ldots \ldots \\
\text { Biaya Pemasaran: }\end{array}$ & ......... & 5.000 & & 50,00 \\
\hline Transportasi...... & 333 & & 3,33 & \\
\hline Kantong plastik............... & 66 & & 0,66 & \\
\hline Konsumsi dan komunikasi.... & $66+$ & & $0,66+$ & \\
\hline Jumlah biaya pemasaran.......... & & $465-$ & & $4,65-$ \\
\hline Keuntungan pemasaran............ & ........ & 4.535 & & 45,35 \\
\hline
\end{tabular}

Tabel 2, menunjukan bahwa, margin pemasaran sebesar $\mathrm{Rp} 5.000 / \mathrm{Kg}$ atau $50 \%$. Margin pemasaran terdiri atas dua komponen yaitu komponen biaya pemasaran dan komponen keuntungan lembaga pemasaran. Pedagang mengeluarkan biaya sebesar Rp 465/kg atau 4,65\% dan memperoleh balas jasa berupa keuntungan sebesar Rp $4.535 / \mathrm{kg}$ atau $45,35 \%$.

Produsen melakukan penjualan pinang mentah kepada pedagang pengecer dengan harga $\mathrm{Rp} 5.000 / \mathrm{kg}$ dan pedagang pengecer melakukan penjualan kepada konsumen akhir dengan harga Rp 10.000/Kg. maka margin pemasaran sebesar $\mathrm{Rp} 5.000 / \mathrm{Kg}$ dengan persentase margin pemasaran terhadap harga yang dibaya oleh konsumen sebesar 50\%. Ini dapat dikatakan margin pemasaran cukup besar. Margin pemasaran sebesar $\mathrm{Rp} 5.000 / \mathrm{kg}$ sesungguhnya terdiri dari biaya pemasaran sebesar Rp 465/kg dan pedagang pengecer memperoleh keuntungan sebesar Rp 4.535/kg. Jika dibandingkan biaya pemasaran dengan keuntungan yang diperoleh maka dapat dikatakan bahwa keuntungan dari pemasaran pinang mentah cukup besar, karena keuntungan mengambil bagian sebesar 45,35\% dari harga pinang mentah yang dibayar oleh konsumen.

\section{Simpulan}

Berdasarkan hasil dan pembahasan dapat ditarik beberapa kesimpulan sebagai berikut: Pemasaran pinang oleh Timor Mitra Niaga desa Wederok melalui 2 saluran, yaitu pemasaran langsung ke konsumen maupun melalui pedagang perantara satu tingkat pasar dengan melibatkan pedagang pengecer Fungsi-fungsi pemasaran yang dilakukan oleh produsen dalam memasarkan pinang mentah berupa fungsi penjualan, fungsi standarisasi dan grading, dan fungsi penanggungan resiko, sedangkan pada tingkat pedagang menjalankan fungsi-fungsi pemasaran pinang mentah berupa fungsi pembelian, fungsi penjualan, fungsi pengangkutan, fungsi penyimpanan, fungsi standarisasi dan grading, fungsi permodalan, fungsi penanggungan resiko dan fungsi informasi pasar. Baik produsen maupun pedagang melakukan fungsi penjualan, fungs standarisasi dan grading, dan fungsi penanggungan resiko. Margin pemasaran pinang mentah sebesar Rp 5.000/kg, yang terdiri dari biaya pemasaran sebesar $\mathrm{Rp} 465 / \mathrm{kg}$ dan pedagang pengecer memperoleh keuntungan sebesar Rp $4.535 / \mathrm{kg}$. Besarnya margin tersebut jika dibandingkan dengan harga yang dibayar oleh konsumen, maka persentase margin pemasaran pinang mentah di Timor Mitra Niaga sebesar 50\%.

\section{Pustaka}

Anindita, R. 2004. Pemasaran Hasil Pertanian. Papyrus,Surabaya.

Hanafie,R .2010. Pengantar ekonomi Pertanian. ANDI. Yogyakarta.

Kanista,M.P, Affiludin,Y \& Batubara,R. 2015. Strategi Pemasaran Pinang (Areca sp,) Studi Kasus Kecamatan Sibolangit, Kabupaten Deli Serdang, Propinsi Sumatera Utara. Peronema Forestry Science Journal Vol 4, No 3:1-8. https//jurnal.usu.ac.id. https://jurnal.usu.ac.id/index.php/PFSJ/issue/view/708

Liat, H.E.K. 2016. Pengaruh Model Pemeraman dan Kondisi Cahaya terhadap Perkecambahan Benih Pinang (Areca catechu L.). Savana Cendana, 1(02) 74-76.

Naimena, F \& Nubatonis, A. 2017. Analisis Pemasaran Pinang Kering Oleh Pedagang di Kecamatan Kota Kefamenanu Kabupaten Timor Tengah Utara. Agrimor 2 (2): 27-29.

Nainahas, K.I. \& Taolin, R.I. 2017. Pengaruh Lama Perendaman Air Kelapa dan Frekuensi Penyemprotan Urin Sapi terhadap Pertumbuhan Bibit Pinang (Areca catechu L.). Savana Cendana, 2(01): 8-10.

Sari, Ita Purnama. 2018. Analisis Efisiensi Pemasaran Pinang Dengan Pendekatan Structure Conduct and Performance (SCP) di Kecamatan Betara Kabupaten Tanjung Jabung Barat. http://repository.unja.ac.id

Sudiyono, A. 2002. Pemasaran Pertanian. Universitas Muhammadiyah Malang, (UMM). Malang.

Susanto,A.B \& Kotler,P. 2000. Manajemen Pemasaran di Indonesia. Salemba Empat.Jakarta. 
Swasta,B \& Irawan. 2001. Manajemen Pemasaran Modern. LibertyTimor Mitra

Niaga. 2018. Data Produksi Pinang Mentah. Desa Wederok.

Kecamatan Weliman. Kabupaten Malaka. 